\title{
A Case Report of Acute Laryngitis with Auricular Lesion: Herpes Zoster Infection with Isolated Vagus Nerve Involvement and Vocal Fold Paresis
}

\author{
Jung-Woo Shin, Sang Woo Kim, Seok-Won Park, and Bo Hae Kim \\ Department of Otorhinolaryngology-Head and Neck Surgery, Dongguk University Ilsan Hospital, \\ Dongguk University College of Medicine, Goyang, Korea
}

\author{
귓바퀴에 미란성 병변을 동반한 비전형적인 급성 후두염 1예: \\ 성대 마비를 동반한 미주신경의 수두대상포진 바이러스 감염 \\ 신정우 · 김상우 · 박석원 · 김보해 \\ 동국대학교 의과대학 일산병원 이비인후-두경부외과학교실
}

\author{
Received January 2, 2020 \\ Revised February 23, 2020 \\ Accepted April 8, 2020 \\ Address for correspondence \\ Bo Hae Kim, MD, PhD \\ Department of Otorhinolaryngology- \\ Head and Neck Surgery, \\ College of Medicine, \\ Dongguk University Ilsan Hospital, \\ 27 Dongguk-ro, Ilsandong-gu, \\ Goyang 10326, Korea \\ Tel $+82-31-961-7438$ \\ Fax $+82-31-961-7427$ \\ E-mail bohae111@naver.com
}

Acute laryngitis and acute inflammatory diseases of either infectious or non-infectious causes have similarities with herpes zoster of the vagus nerve (VHZ). We present a case which was initially diagnosis wtih acute laryngitis but finally diagnosed as VHZ. A 41-year-old male presented with an ongoing fever, throat pain and right otalgia lasting for two days with worsening symptoms despite nonsteroidal anti-inflammatory drug medication. Initially, he was treated conservatively as acute laryngitis was suspected. However, VHZ was subsequently diagnosed in this patient after considering unilateral auricular and laryngeal vesicles which were followed by ipsilateral vocal fold paresis. An antiherpetic agent and prednisolone were administered upon the presentation of vocal fold paresis. Axonotmesis was discovered by laryngeal electromyography one week after the appearance of vocal fold paresis. All symptoms subsided after one month. These results highlight the importance of understanding vagus nerve function in developing a differential diagnosis for laryngitis and VHZ.

Korean J Otorhinolaryngol-Head Neck Surg 2021;64(3):188-91

Key Words Electromyography · Herpes zoster - Vagus nerve ·

Varicella zoster virus infection.

\section{Introduction}

Acute laryngitis is an acute inflammatory condition of the larynx with either infectious or non-infectious etiology. ${ }^{1)} \mathrm{Al}-$ though acute laryngitis is clinically diagnosed and usually self-limiting disease, attention should be given to diagnosis and treatment in atypical cases. ${ }^{2)}$ Branch of the vagus nerve innervates each side of the larynx providing sensory func-

This is an Open Access article distributed under the terms of the Creative Commons Attribution Non-Commercial License (https://creativecommons.org/licenses/by-nc/4.0) which permits unrestricted non-commercial use, distribution, and reproduction in any medium, provided the original work is properly cited. tion. Therefore, acute laryngitis can be clinically similar to herpes zoster infection of the larynx when varicella zoster virus (VZV) affects the vagus nerve. ${ }^{3)}$ A significant diagnostic finding of herpes zoster of the vagus nerve (VHZ) is unilateral vesicular eruption of the larynx as observed by laryngoscopy. However, VHZ is not typically suspected because of its rare occurrence. ${ }^{4)}$ Thus, understanding vagus nerve function and the manifestations of $\mathrm{VHZ}$ are important for proper diagnosis. Herein, we report a case of VHZ that initially presented with acute laryngitis followed by vocal fold paresis. 


\section{Case}

A 41-year-old male presented with ongoing fever, throat pain and right otalgia lasting for two days with worsening symptoms despite nonsteroidal anti-inflammatory drug (NSAID) medication (talniflumate $370 \mathrm{mg}$, three times/day). There was no underlying disease other than well controlled type II diabetes mellitus. The patient presented with laryngeal swelling limited to the right aryepiglottic fold, which was discovered during laryngoscopy. However, no definite lesions were identified on the tympanic membrane, external auditory canal, or auricle. The patient was hospitalized with severe throat pain and dehydration.

Leukocytosis was observed on laboratory examination indicating possible bacterial laryngitis. Therefore, antibiotics and an NSAID were administered. However, skin vesicles on the right auricle (cavum area) and ipsilateral laryngeal ulcers on the right side of the epiglottis and the aryepiglottic fold occurred one day after admission (Fig. 1A and B). VHZ was suspected because these areas are innervated by sensory branches of the vagus nerve. VZV polymerase chain reaction (PCR) and a Tzank smear were performed. Although results of Tzank test were negative, typical vesicles were present on the auricle and larynx. Therefore, the patient was treated with an antiherpetic agent (famciclovir $750 \mathrm{mg} /$ day).

The day after vesicular eruption of auricle and the larynx, the patient suddenly complained of hoarseness. Impairment of right vocal fold mobility was observed by laryngoscopy (Fig. 1C and D). Movements of tongue, uvula, and shoulder were normal. In addition, there was no facial palsy or nystagmus, and Rinne and Weber tests were also normal. Contrast computed tomography of the neck was performed for differential diagnosis of other diseases causing impairment of vocal fold mobility. There was no pathological lesion except dilatation of the right pyriform sinus. Prednisolone ( $40 \mathrm{mg} /$ day) was given for five days while monitoring blood glucose to minimize additional nerve damage and prevent postherpetic neuralgia. Fever and pain subsided four days after hospitalization, which was a week after the onset of symptoms. VZV DNA PCR and IgM serologic test results were negative upon disappearance of symptoms.

Laryngeal electromyography (EMG) was performed on both the cricothyroid and thyroarytenoid muscles one week after right vocal fold paresis appeared. Positive sharp waves (PSW) were detected on the right cricothyroid muscle in the resting state, and motor unit action potential of the right cricothyroid muscle (size and number of muscle fibers) was reduced during phonation. This may have been due to nerve damage (Fig. 2). However, EMG evaluation of the thyroarytenoid muscle failed despite several attempts because of severe pain during needle insertion and muscularity of the patient's neck. Improvement in laryngeal ulcers and auricular skin vesicles was observed within two weeks after the appearance of symptoms, and vocal fold mobility completely recovered after one month.

\section{Discussion}

The vagus nerve originates at the medulla oblongata of the brainstem and controls the autonomic nervous system, sensory action of various organs, and motor function of some skeletal muscles. ${ }^{3)}$ Since the main manifestation of herpes zoster (HZ) infection is a skin or mucosal lesion appearing in an area that is innervated by an infected nerve, the location of vesicles indicates which nerve is affected by VZV infection. ${ }^{5,6}$ Thus, VHZ was suspected in this patient because of the observation of vesicular lesions in the ipsilateral auricle and larynx. In addition, accompanying ipsilateral vocal fold paresis made VHZ more likely based on the function of the vagus nerve. Although specific serum antibody titers and VZV PCR exhibit high sensitivity and specificity in the diagnosis of $\mathrm{HZ}$, it is important to consider that false negatives may be seen in the acute phase of $\mathrm{HZ}$ infection or in immunocompromised patients. ${ }^{7)}$ In the literature review, VZV infection of cranial nerve
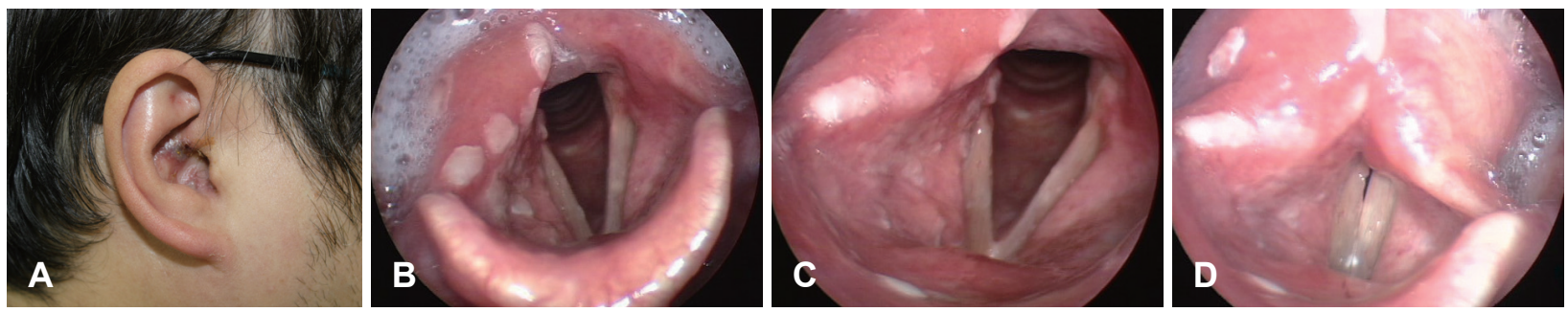

Fig. 1. Clinical manifestations. Multiple vesicles on right concha cavum area (A). Mucosal ulcerative lesions on right side of the larynx (B). Full abduction view of vocal folds (C). Full adduction view of vocal folds (D). 

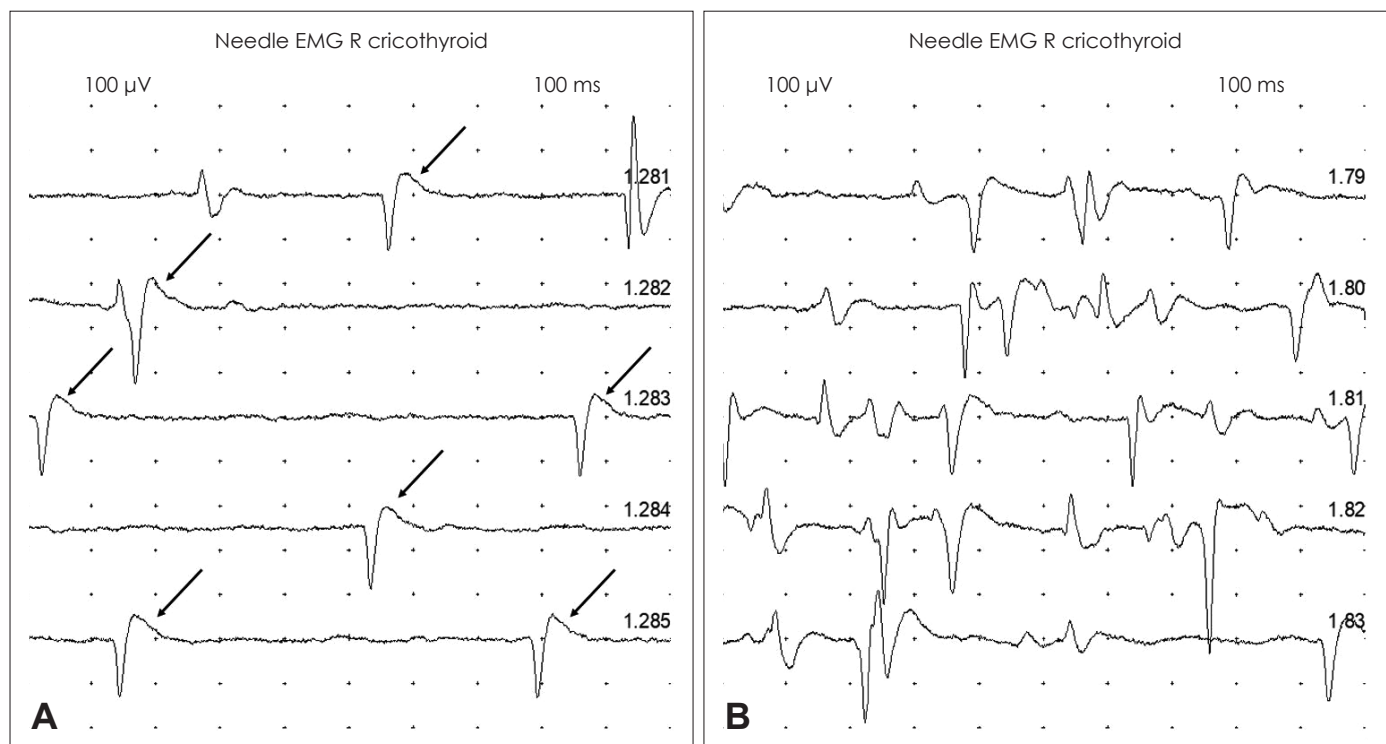

Fig. 2. Laryngeal EMG of right CT muscle after a week after vocal fold paresis. Positive sharp waves (arrows) were detected on laryngeal EMG from right CT muscle after a week after injury (A). Decreased motor-unit action potentials at right CT muscle (B). EMG: electromyography, CT: cricothyroid.

generally present as multiple cranial neuropathies, and isolated vagus nerve involvement of $\mathrm{HZ}$ has been reported only a few cases. ${ }^{5,8)}$ Thus, understanding the functions of the vagus nerve is critical for differential diagnosis of $\mathrm{VHZ}$ or acute laryngitis.

Attention should be given to patients infected with $\mathrm{HZ}$ to minimize the risk of permanent nerve dysfunction, postherpetic neuralgia, and motor nerve palsy. Injury of the infected nerve is the pathogenic cause of neuropathy upon VZV reactivation. This injury is due to inflammation or impairment of vascular circulation followed by permanent scarring. Antiherpetic agents are known to reduce acute pain, duration of viral shedding, and risk of postherpetic neuralgia in $\mathrm{HZ}$ infection. ${ }^{9)}$ In addition, steroid therapy is an important option for treatment $\mathrm{HZ}$ infection and is also widely used in patients with Ramsay Hunt syndrome. ${ }^{10)}$ Although the use of steroids for the recovery of vocal fold mobility in general idiopathic vocal fold palsy is controversial, steroid use may be helpful for reducing postherpetic pain and improving the prognosis of VHZ by minimizing further nerve injury. ${ }^{11}$

Although vocal fold paresis can be simply diagnosed by laryngoscopy, electrophysiologic tests such as electroneurography or EMG are performed for the diagnosis and prognosis of injury to motor nerves. ${ }^{12,13)}$ Nerve damage is generally classified into three types: neurapraxia, axonotmesis, and neurotmesis, which are considered first-, second-, and third-degree injuries, respectively. Neuraparaxia is predominantly caused by blunt trauma and causes a temporary conduction block with demyelination. Axonotmesis is axonal loss associated with preservation of connective tissue layers. Neurotmesis is the disruption of the nerve and nerve sheath with only partial recovery. This classification system is helpful for understanding the degree of nerve injury and prediction of motor function recovery. The timing of EMG implementation is recommended 2-3 months after nerve injury since there is minimal risk of further degradation of nerve function and relatively accurate prediction of recovery at that time. ${ }^{14)}$ PSW (spontaneous action potential from denervated muscle fiber) was detected one week after vocal fold paresis in the case described herein. Since PSW is generally detected within 1-2 weeks after neuropathies, this finding indicated that recovery of nerve conduction was likely due to the preservation of the connective tissue layer. In the current case, we observed diagnostically relevant PSW and predicted recovery of vocal fold mobility shortly after injury. However, we were able to detect PSW in only cricothyroid muscle, but not in thyroarytenoid muscle. EMG evaluation of thyroarytenoid muscle was impossible despite several attempts in this patient because of severe pain upon needle insertion. Thus, we should keep in mind that EMG of the thyroarytenoid muscle may not be possible in obese or uncooperative patient. ${ }^{15)}$

A thorough understanding of vagus nerve function is important for the differential diagnosis of laryngitis and VHZ. Careful physical examination including laryngoscopy is an essential procedure. In addition, early EMG also may help to estimate the degree of nerve injury and predict recovery of vocal fold mobility. 


\section{Acknowledgments}

There are no conflicts of interest or funding source to declare.

\section{Author Contribution}

Conceptualization: Bo Hae Kim, Seok-Won Park. Data curation: Sang Woo Kim. Formal analysis: Bo Hae Kim. Methodology: Bo Hae Kim. Supervision: Bo Hae Kim. Visualization: Sang Woo Kim, Jung-Woo Shin. Writing - original draft: Jung-Woo Shin. Writing - review \& editing: Jung-Woo Shin, Bo Hae Kim.

\section{ORCID}

Bo Hae Kim https://orcid.org/0000-0002-4645-0678

\section{REFERENCES}

1) Chandler M, Mintz ML. Laryngitis and hoarseness. In: Mintz ML, editor. Disorders of the Respiratory Tract: Common Challenges in Primary Care. Totowa, NJ: Humana Press;2006. p.89-99.

2) Reveiz L, Cardona AF. Antibiotics for acute laryngitis in adults. Cochrane Database Syst Rev 2013;(3):CD004783.

3) Câmara R, Griessenauer CJ. Anatomy of the vagus nerve. In: Tubbs RS, Rizk E, Shoja M, Loukas M, Barbaro N, Spinner R, editors. Nerves and Nerve Injuries. Amsterdam: Elsevier;2015. p.385-97.

4) Watelet JB, Evrard AS, Lawson G, Bonte K, Remacle M, Van Cauwenberge $\mathrm{P}$, et al. Herpes zoster laryngitis: Case report and serological profile. Eur Arch Otorhinolaryngol 2007;264(5):505-7.

5) Joo T, Lee YC, Kim TG. Herpes zoster involving the abducens and vagus nerves without typical skin rash: A case report and literature review. Medicine (Baltimore) 2019;98(19):e15619.
6) Van Den Bossche P, Van Den Bossche K, Vanpoucke H. Laryngeal zoster with multiple cranial nerve palsies. Eur Arch Otorhinolaryngol 2008;265(3):365-7.

7) Baiker A, Haase R, Eberle J, Vizoso Pinto MG, Pfrepper KI, Petrich A, et al. Early detection of varicella-zoster virus (VZV)-specific $\mathrm{T}$-cells before seroconversion in primary varicella infection: Case report. Virol J 2010;7:54.

8) Park BS, Park HS, Lee HJ, Koo SK. A case of herpes zoster laryngitis with isolated vagus nerve paralysis, Korean J OtorhinolaryngolHead Neck Srg 2010;53(10):636-9.

9) Dworkin RH, Johnson RW, Breuer J, Gnann JW, Levin MJ, Backonja $\mathrm{M}$, et al. Recommendations for the management of herpes zoster. Clin Infect Dis 2007;44 Suppl 1:S1-26.

10) Jeon Y, Lee H. Ramsay Hunt syndrome. J Dent Anesth Pain Med 2018;18(6):333-7.

11) Masroor F, Pan DR, Wei JC, Ritterman Weintraub ML, Jiang N. The incidence and recovery rate of idiopathic vocal fold paralysis: A population-based study. Eur Arch Otorhinolaryngol 2019;276(1): $153-8$.

12) Wang CC, Chang MH, Wang CP, Liu SA. Prognostic indicators of unilateral vocal fold paralysis. Arch Otolaryngol Head Neck Surg 2008;134(4):380-8.

13) Lee DH. Clinical efficacy of electroneurography in acute facial paralysis. J Audiol Otol 2016;20(1):8-12.

14) Robinson LR. Traumatic injury to peripheral nerves. Jpn J Rehabil Med 2005;42(2):89-98.

15) Focquet A, Péréon Y, Ségura S, Ferron C, Malard O, Espitalier F. Diagnostic and prognostic contribution of laryngeal electromyography in unilateral vocal-fold immobility in adults. Eur Ann Otorhinolaryngol Head Neck Dis 2017;134(1):13-8. 